\title{
Additives for Conducting Polymer Membrane from Coal
}

\author{
Atma Ram Singh*, Debapriya Choudhury, Gora Ghosh and Sunil K. Srivastava
}

Central Institute of Mining \& Fuel Research, Digwadih Campus, (Erstwhile Central Fuel Research Institute), P.O. FRI, Dhanbad - 828108, Jharkhand, India

\begin{abstract}
For the first time, an additive for conducting polymer membrane has been prepared from an Indian coal. Samla coal from Raniganj coalfield having $80 \%$ carbon on dmmf basis was first demineralised chemically and then degraded by oxidizing it with oxidizing agent followed by solubilization of oxy coal thus produced in polar organic solvent. The soluble part of the coal was dried and the solid residual part along with a neutral base material polyvinyl alcohol was used for making additive for conducting polymer membrane in the form of a coloured thin film. The quality of the film $/$ membrane made has been extremely good and the conductance is in the range of $10^{-3}$ to $10^{-4}$ units $\left(\mathrm{Scm}^{-1}\right)$. Due to non explanation of enhancement in carboxylic acid functional groups, on oxidation, from $1.2 \%$ to $18.3 \%$ by the Mazumdar's proposed model coal structure, an anomaly with respect to 9-10 position of phenanthrene is observed and reported here and a correction to this has been proposed which explains the experimental results.
\end{abstract}

Keywords: Coal, additive, conducting polymer membrane.

\section{INTRODUCTION}

The growing importance of high performance engineering plastics, high molecular weight conducting polymers, temperature and other sensors, membranes etc, and their usage in different Industries are now very well known. In today's context, the cost of production of such materials is exhorbitantly high. Thus, there is an urgent need to develop processes for preparing good quality materials as mentioned above in lesser number of steps and at a cheaper cost. An attempt has been made for the first time to get an additive from coal for preparing a conducting polymer membrane in the form of a coloured thin film. A numbers of model structures of coal have been put forward by different researchers working in the area of coal science. One such model structure of coal had been proposed by Mazumdar. During the course the experimental work, the results obtained is expected to be explained by this formula. If this proposed structure of coal is not able to explain the any of the results then modification in the proposed coal structure is very much desired. Here in this paper short modification in Mazumdar's formula has been proposed.

\section{EXPERIMENTAL}

\subsection{Characterization of Raw and Treated Coals}

Detailed characterization of raw Samla coal and the demineralised Samla coal were done following IS methods. The methods for determinations of major elemental compositions and functional groups have described in an earlier publication made from this laboratory [1]. Samla coal was taken in a flat bottom flask and to this, added an oxidizing agent for carrying out oxidation at desired

*Address correspondence to this author at the Central Institute of Mining \& Fuel Research, Digwadih Campus, (Erstwhile Central Fuel Research Institute), P.O. FRI, Dhanbad - 828108, Jharkhand, India; Tel: 091326 2388362; Fax: 0913262388360 ;

E-mails: arscfri@yahoo.co.in, arscimfr@rediffmail.com temperature for desired time. After completion of the reaction, the oxy coal was washed with distilled water and filtered. The residual mass i.e. oxy coal was extracted using polar organic solvent. The solid soluble part of organic solvent extract was taken out after solvent removal followed by its characterization. The above data are summarized in (Table 1).

\subsection{Preparation of thin Film}

A thin film was prepared using this solid product with a neutral base material polyvinyl alcohol. No impurity was found to be present in neutral base material polyvinyl alcohol used which may lead to any conductance. Similarly raw coal or demineralised coal did not have any conductance value. Thin film membranes were also prepared using other copolymers but success could not be achieved due to its non uniformity and its brittleness.

\subsection{Conductivity Measurement}

This thin film was characterized at IIT Kharagpur for conductivity. The conductivity measurements were made at room temperature $\left(25^{\circ} \mathrm{C}\right)$. The conductivity cell is composed of two stainless steel electrodes of $16 \mathrm{~mm}$. diam. Membrane sample was sandwiched in between stainless steel electrodes. An impedance spectra of the membranes were recorded from $40 \mathrm{~Hz}$ to $110 \mathrm{MHz}$ amplitude of $10 \mathrm{mV}$ using an HP Agilent 4294A Precision Impedance Anal Bulk resistance of the membrane was determined from high frequency in the imaginary component of impedance with real axis. The conductance was calculated using the following equation If= I/ R.A Where If, I, R and A denote the membrane conductivity, membrane thickness, bulk resistance of the membrane and cross section area of the membrane respectively. The data are shown in (Table 2 ). 
Table 1. Characterization of Raw and Demineralised Samla Coal, Oxy coal \& Soluble Part of Oxy Coal in Polar Organic Solvent

\begin{tabular}{|c|c|c|c|c|}
\hline Moisture \%* & 8.6 & 1.7 & 9.1 & 7.9 \\
\hline Carbon \% (dmf) & 80.6 & 80.5 & 62.3 & 59.7 \\
\hline Hydrogen $\%(\mathrm{dmf})$ & 4.5 & 4.6 & 2.9 & 4.5 \\
\hline $\mathrm{O}_{\mathrm{OH}} \%(\mathrm{dmf})$ & 4.8 & 5.2 & 5.0 & 2.0 \\
\hline $\mathrm{O}_{\mathrm{COOH}} \%(\mathrm{dmf})$ & 0.96 & 1.2 & 18.3 & 12.6 \\
\hline $\mathrm{C}_{\mathrm{CH} 3} \%(\mathrm{dmf})$ & 3.1 & 2.4 & 1.0 & 0.8 \\
\hline
\end{tabular}

Table 2. Conductivity of Coal Derived Value Added Product (in Units $\mathrm{Scm}^{-1}$ )

\begin{tabular}{|c|c|c|}
\hline Sample No. & Loading of Coal Derivative (\%) & Conductivity \\
\hline \hline $\mathrm{S}_{1}$ & 10 & $2.15 \times 10-4$ \\
\hline $\mathrm{S}_{1}$ & 20 & $1.49 \times 10-3$ \\
\hline $\mathrm{S}_{2}$ & 5 & $7.11 \times 10-4$ \\
\hline $\mathrm{S}_{2}$ & 10 & $6.39 \times 10-4$ \\
\hline $\mathrm{S}_{2}$ & 20 & $2.199 \times 10-3$ \\
\hline$* \mathrm{~B}$ & 15 & $\mathrm{NM}$ \\
\hline *C & 10 & $\mathrm{NM}$ \\
\hline \\
'S' series samples were on a neutral base material (polymer). \\
'B \& C' are on other co-polymer. \\
*Could not be measured due to brittleness and non uniformity of the film.
\end{tabular}

\subsection{Recording of FTIR Spectra}

FTIR spectra of raw, demineralised and oxy Samla coals were recorded. About $0.005 \mathrm{~g}$. of sample was weighed accurately and mixed with 200 times weight of $\mathrm{KBr}$ to obtain a mixture of $0.5 \%$ of sample in $\mathrm{KBr} .250 \mathrm{mg}$ of the mixture was then weighed and pressed into pellets using evacuable die at 10 tons of pressure. The pellet was dried in vacuum oven at $70^{\circ} \mathrm{C}$ for $48 \mathrm{hrs}$ and the spectra were recorded using a Perkin Elmer Spectrum GXFTIR spectrometer by coadding 50 interferograms at $2 \mathrm{~cm}^{-1}$ resolution.

\section{RESULTS AND DISCUSSION}

\subsection{Characterization of Raw and Demineralised Samla Coal}

Table 1 Summarizes the proximate, elemental and functional groups analyses of raw and demineralised Samla coal as well as that of oxy coal and soluble part of oxy coal in polar organic solvent for ready comparison. On careful examination of the above table, it is observed that the ash content has been drastically reduced from $14.6 \%$ to $1 \%$ and the moisture content of demineralised coal is reduced to $1.7 \%$ from $8.6 \%$. Except these, practically no change in Carbon, Hydrogen and nitrogen percentages occurred. Even in functional groups, not major changes have been observed.
It is worth mentioning here that after demineralization of Samla coal, no impurity leading to any conductance value, is found to be present in the demineralised samla coal. It was essential every time to check that ions are not present on the surface of the oxy- coal otherwise it will affect the conductivity of the thin film or conducting polymer membrane to be prepared. After oxidation of samla coal, it is observed from Table 1 that carboxylic acid functional groups have enhanced from $1.2 \%$ to $18.3 \%$. This order of enhancement in carboxylic acid functional groups at the periphery of aromatic rings can be explained only when these have come mainly from $9-10$ position in angle ring aromatic nucleus like phenanthrene. This is an anomaly in model structure of coal proposed by Mazumdar [2]. Methylene and methyl groups present in this coal are only about $3-4 \%$ and the reduction of methyl group from this level to $1 \%$ level alone cannot explain [3] the generation of carboxylic acid functional groups of the order of $18.3 \%$.

Table 1 also summarizes the percentages of carbon, hydrogen and nitrogen on dry mineral matter free basis of oxy coal and soluble oxy coal besides that of raw and demineralised Samla coals. It is observed that there is practically no change in characterization data of raw and demineralised samla coal as stated earlier. When these are compared with the characterization data of oxy coal, it is found that the percentage of moisture, ash and nitrogen in oxy coal is much higher than that of the corresponding value in demineralised coal while carbon and hydrogen percentage have been drastically reduced. The above facts can be explained on the basis of loss of carbon and hydrogen contents occurred during oxidation of samla coal. Percent of methyl group has been reduced due to its oxidation to carboxylic acid functional groups during oxidation. There was no drastic change observed in hydroxyl functional group percentage which can be attributed to the simultaneous creation of new hydroxyl groups in the coal matrix as well as conversion of already present hydroxyl groups into carbonyl groups. The characterization data of the organic solvent soluble part of the oxy coal confirms the presence of hydroxyl, carboxyl and small amount of methyl functional groups. During nitric acid treatment as explained earlier [46] oxidation and substitution of nitro groups takes place at reactive sites of coal matrix which enhances its solubility in acetone. 


\subsection{Anomaly in Model Coal Structure Proposed by Mazumdar}

The model structure of samla coal $(80-83 \% \mathrm{C})$ as proposed by Mazumdar [2] is as shown in Fig. (1). On careful examination of the above model structure of coal, it is crystal clear that 9,10 position of each phenanthrene unit is blocked by either functional groups or by other linkages. If it is so, then the sharp enhancement in carboxylic acid functional groups from 1.2 to $18.3 \%$ cannot be explained by taking this structure as corrected which is an anomaly. Let us find out a way to explain the actual experimental results. This can only be done if the Mazumdar's [2] formula is modified in such a way that not only this results but all other experimental observation are explained. It is known that the mechanism of oxidation followed by hydrolysis of phenanthrene in which 9,10 position are available, gives a product generating carboxylic and hydroxyl groups as follows $[7,8]$.
9,10 position of phenanthrene of each unit are not blocked. It is either vacant in coal structure or present in the form of 9,10 dihydrophenanthrene. Many of the model structure proposed, i.e Lander's [10] and Gibson [11], are 'two dimensional". Although the presence of folded rings such as 9-10 dihydrophenanthrene means that the structure are not flat as shown in Fig. (2). Pitt [12] has proposed model of coal structure based on 9,10- dihydrophenanthrene structures Fig. (3) and that these molecules exist in a tangled state in coal. Heredy and Wender (Fig. 4) proposed model of coal structure $(83-84 \% \mathrm{C})$ indicating the availability of 9,10dihydrophenanthrene and phenanthrene units in coal which are linked with each other by ether and methylene bridge. The angle aromatic rings like phenanthrene is the mother nucleus of coal. Based on its rank, association of different functional groups in different proportions with other units of coal by methylene and by ether linkages [13-15] are reported in literature. It is also known that this linkage is less reactive towards oxidation hence it cannot explain the above result.

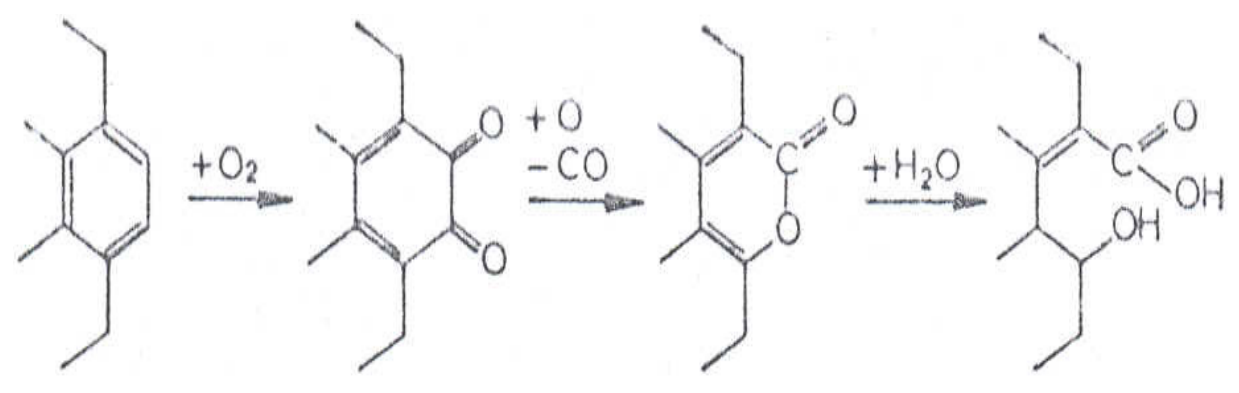

In some cases, it is known that oxidation facilitates at benzylic and 9,10 position of phenanthrene units yielding a product containing more number of carboxylic acid functional groups as follows [9].
By virtue of vast literature available on oxidation of condensed aromatic rings, it is obvious that the 9-10 position of phenanthrene is more reactive towards oxidation rather than other sites $[13,14,16]$. Thus, during oxidation preferably

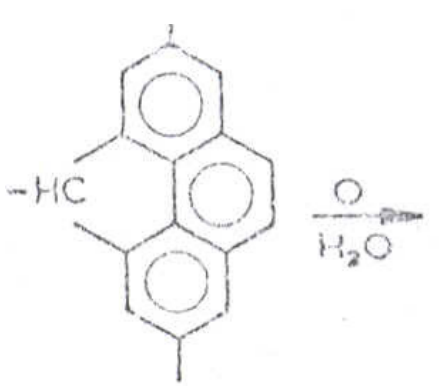

In the present case, as also in earlier publication [1], it was observed that samla coal was easily oxidized by oxidizing agents. Hence as per above, it is concluded that dissociation of this bond takes place. In a previous work [3] it was observed that not only the carboxylic acid functional groups are generated on oxidation of coal but subsequently

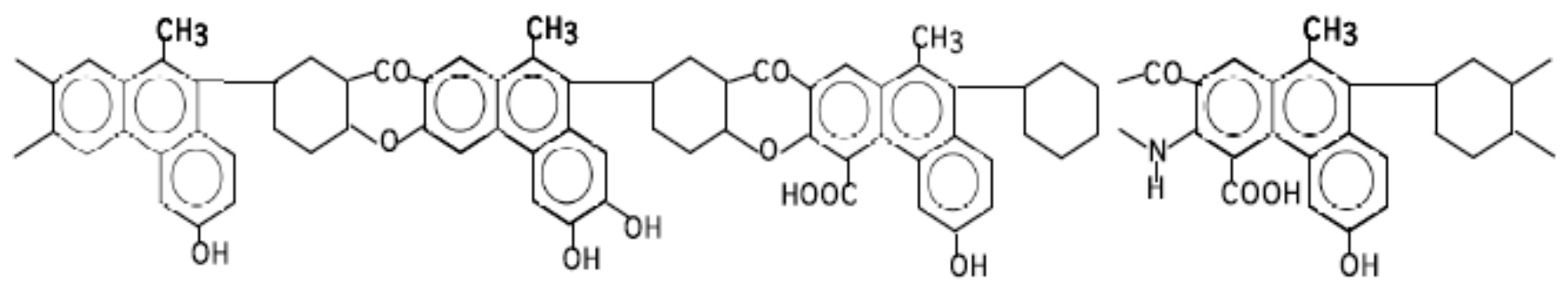

Fig. (1). 
the nitro groups are also substituted in the periphery of aromatic structure in coal matrix. Thus, creation of carboxylic acid functional groups in the coal matrix takes place first and then nitration occurs, so that nitro groups substitute at meta position with respect to carboxylic acid functional groups which is meta-directing as shown in Reaction- 1. The quantity of $\mathrm{OH}$ functional groups remained practically the same (Table 1 ) on oxidation of demineralised coal to oxy-coal $[4,5]$. The above data clearly indicates the availability of 9,10 position of phenanthrene type of aromatic ring in coal which are responsible for generating large amount of carboxylic acid functional groups.

\subsection{FTIR Spectra of Raw, Demineralized and Oxy Samla Coals}

It can be seen, from Figs. $(\mathbf{5}, \mathbf{6})$ that there is no peak for $\mathrm{NO}_{2}$ in raw Samla coal as well as in demineralised samla coal but in the FTIR Spectra of oxy Samla coal (Fig. 7) there are two distinct peaks at $1336.40 \mathrm{~cm}^{-1}$ and $1539.17 \mathrm{~cm}^{-1}$ corresponding to nitro group indicating that during nitric acid oxidation, nitro group has been introduced in the coal structure. These are due to symmetric and asymmetric stretching vibrations of aromatic nitro groups. Strong peak at $1716.12 \mathrm{~cm}^{-1}$ in oxy Samla coal is indicative of-COOH groups formed on oxidation. Similarly enhanced peak at

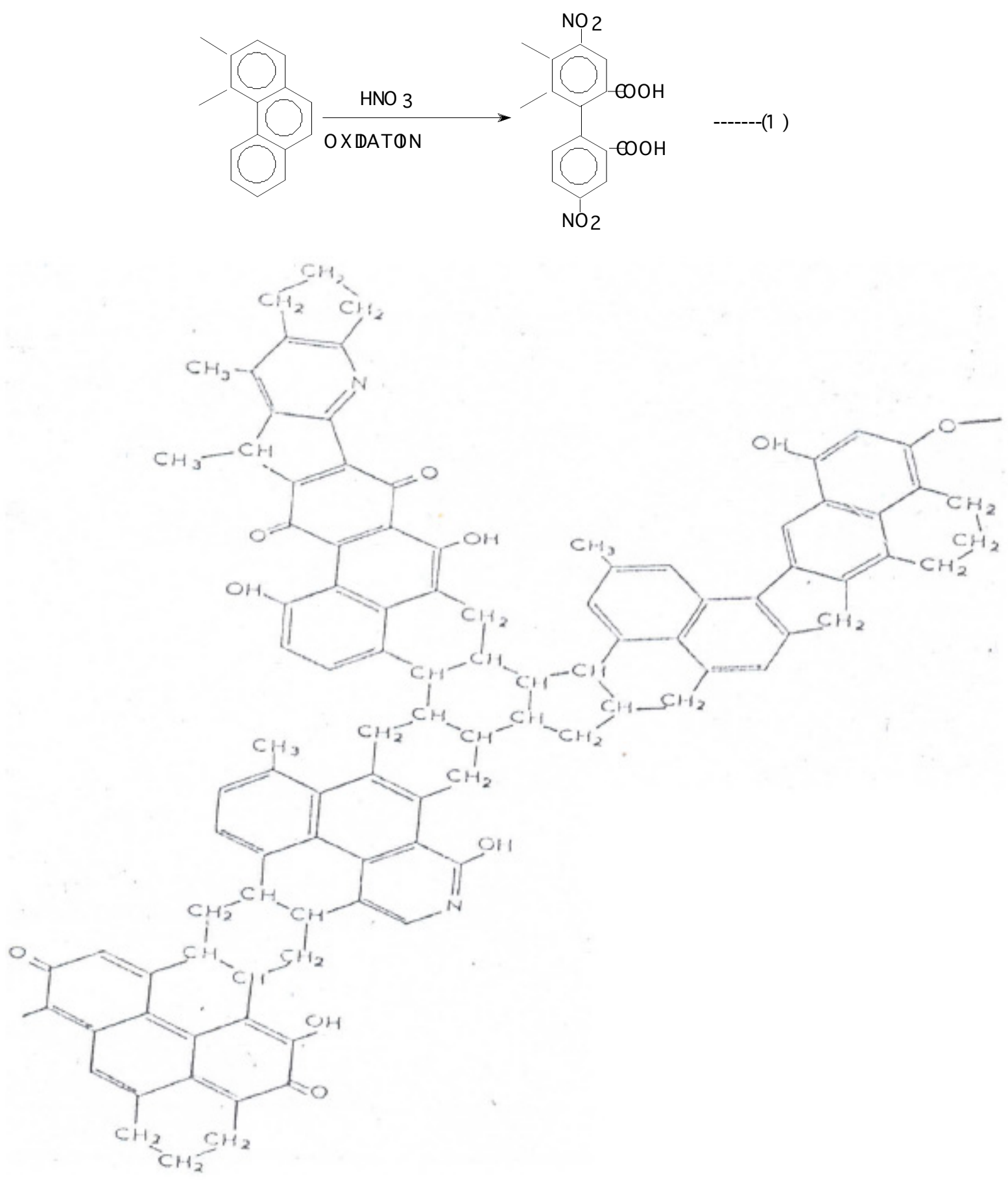

Fig. (2). 

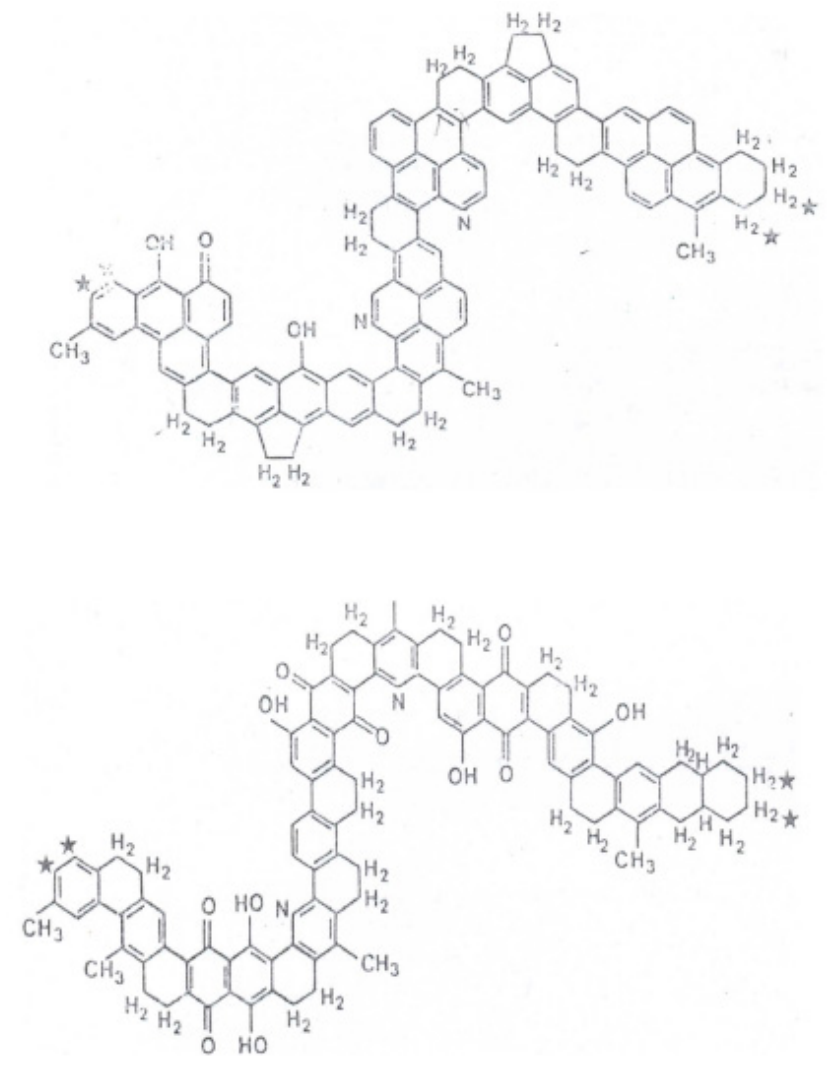

Fig. (3).

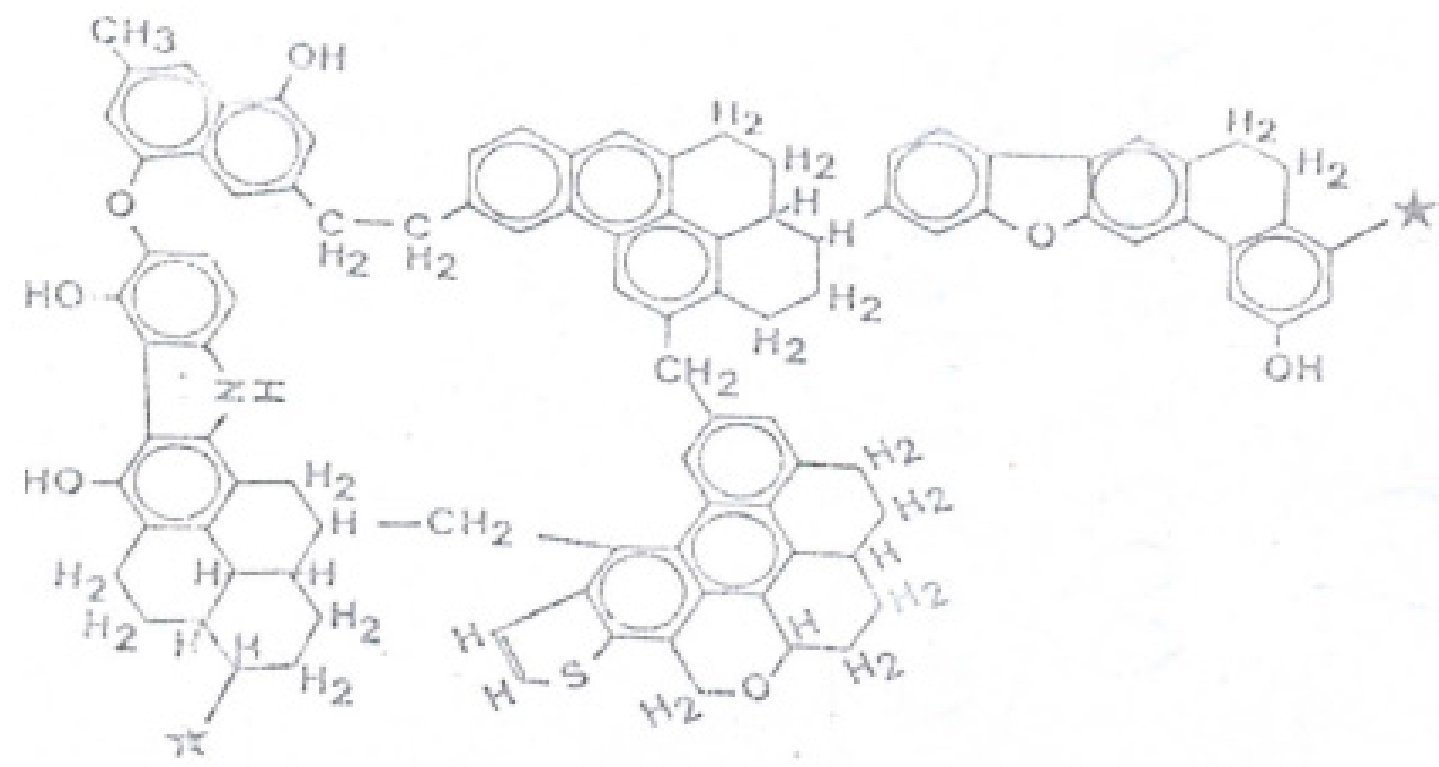

Fig. (4).

$3424.25 \mathrm{~cm}^{-1}$ in oxy Samla coal is indicative of $-\mathrm{OH}$ functional groups in oxy Samla coal slight decreases in aliphatic groups in oxy Samla coal is indicated by peaks at $2922.5 \mathrm{~cm}^{-1}$ and $2848.70 \mathrm{~cm}^{-1}$.

\subsection{Conductivity of Organic Thin Films Produced}

Solvent extracts of oxy-coals have been used to produce organic thin films. HPLC chromatogram of solvent extract of oxy-coal is given in Fig. (8). After a series of attempts at IIT, Kharagpur, thin films of solvent extract over a neutral base material polyvinyl alcohol have been prepared \& tested for its conductance. The materials were found to be conducting $\left(10^{-3}\right.$ to $10^{-4}$ units $\left(\mathrm{Scm}^{-1}\right)$. It is well-known that the graphite (only carbon) is a good conductor. It is also known that polymers which contain hydrogen beside carbon such as polyethylene or which contains oxygen beside carbon such as polyvinyl alcohol etc. is not conducting. A conjugated system may lead to conducting properties of organic compounds [17-19]. As, in a conjugated system, the electrons are only loosely bound, electron flow may be 


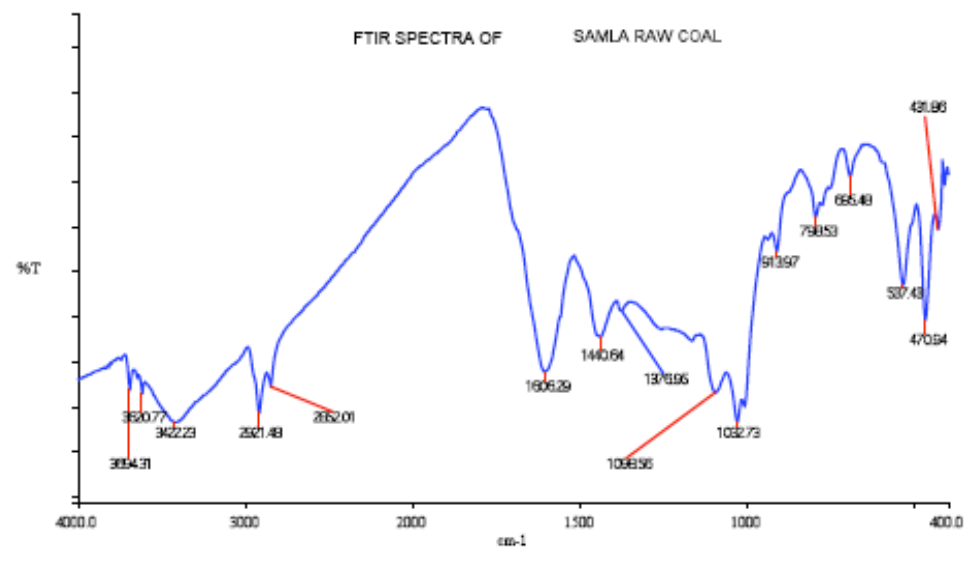

Fig. (5).

FTIR spectra of Demineralised Samla coal

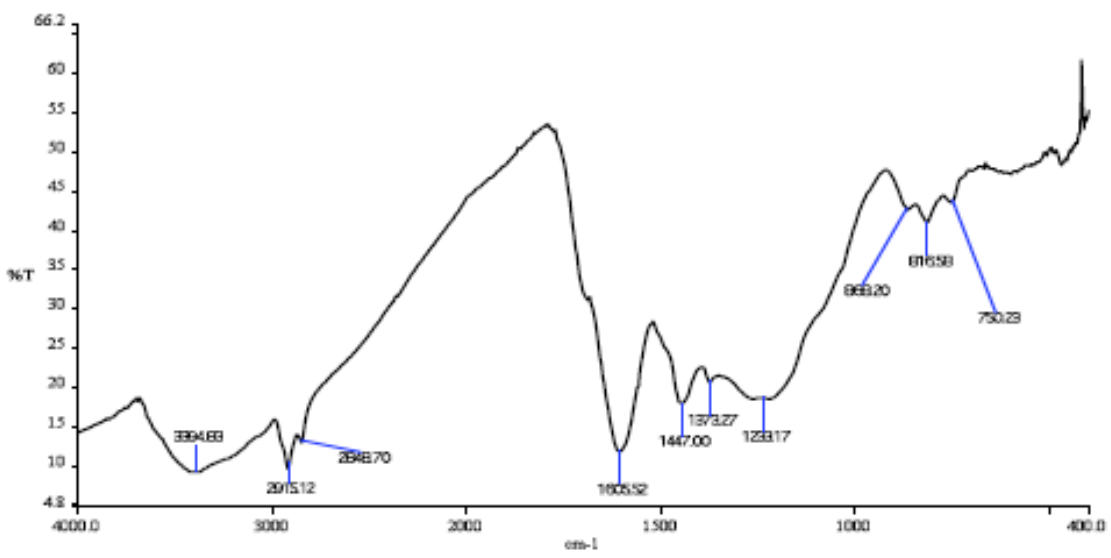

Fig. (6).

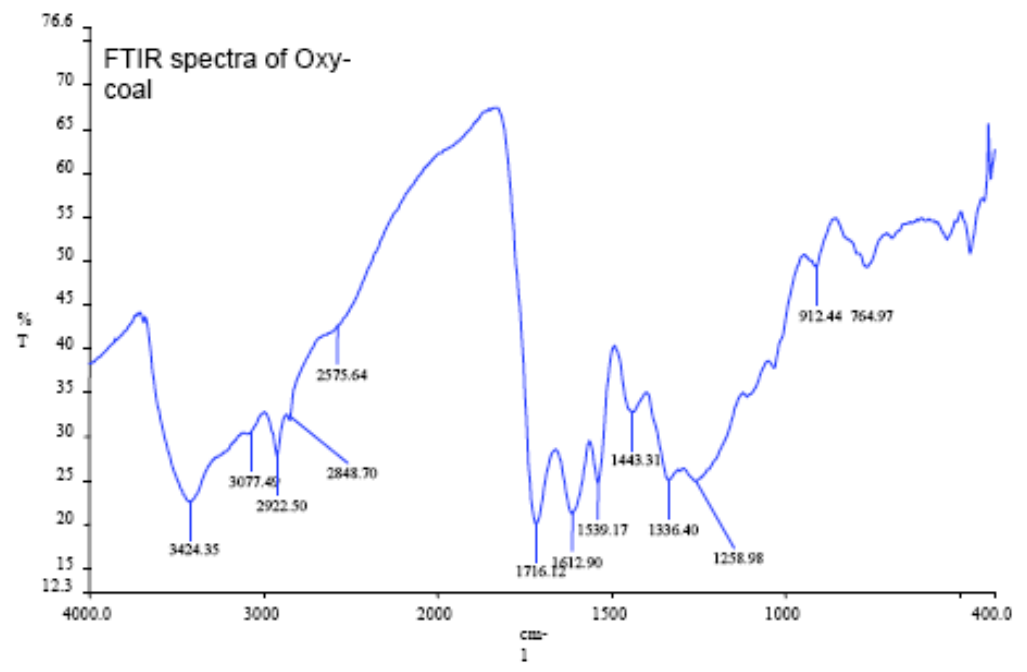

Fig. (7).

possible. However as the polymers are covalently bonded, these materials need to be doped with such materials which facilitate electron flow. Doping is done either by the addition of electrons (reduction reaction) or by the removal of electrons (oxidation reaction) from the polymers. Once doping has occurred, the electrons in the pi-bonds are able to 'jump' around the polymer chain. As the electrons are moving along the molecule, an electric current flow occurs.

However the conductivity of the material is limited as the electrons have to 'jump' across the molecules. So, for better conductivity, the molecules must be well ordered and closely packed to limit the distance 'jumped' by the electrons. This 


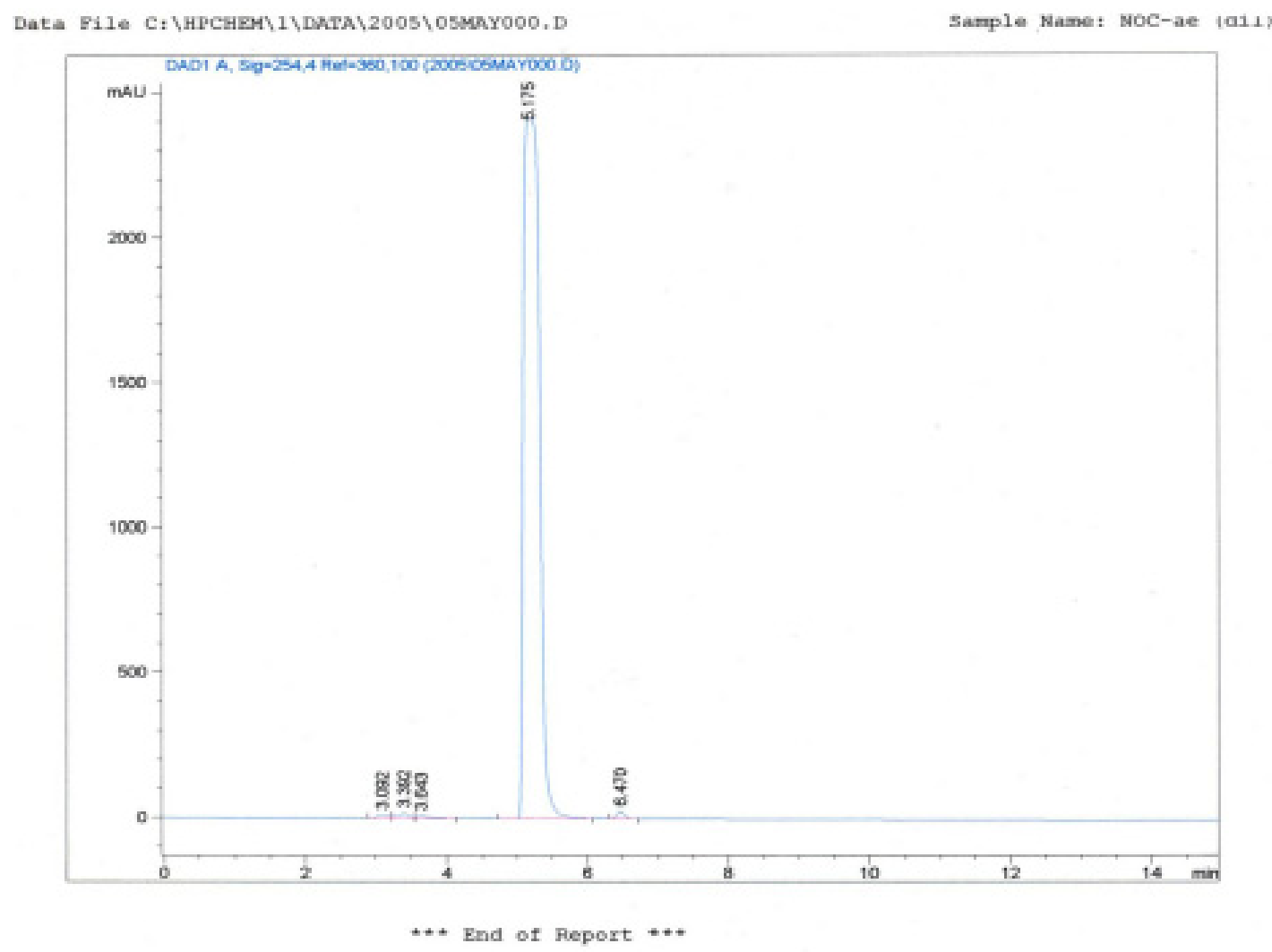

Fig. (8). Oxy coal in organic solvent [Mobile Phase- Methanol: water =80:20; Flow Rate=0.5 ml/min].

occurs better in trans undoped polyactelyene. By doping, the conductivity of the polymer increases from $10^{-3} \mathrm{~S} \mathrm{~cm}^{-1}$ to $3000 \mathrm{Scm}^{-1}$. An oxidative doping (removal of electrons) can be done using iodine. The iodine attracts an electron from the polymer from one of the pi bonds. Thus, the remaining electrons can move along the chain. In this phenomenon, the charge transport properties of conjugated molecules are intrinsically correlated with their crystalline structure, with the degree of orientation and with grain size. Hence, controlling and optimizing film quality is essential to achieve the conductivity.

Seven such films were prepared on known neutral base material polyvinyl alcohol and on some other co-polymers. Those films with other copolymers could not be found to be uniform in thickness as well as they had brittleness. Hence, the results were not found to be encouraging (Table $\mathbf{2 B}, \mathbf{C}$ ). But when organic solvent extract was deposited over known neutral base material polyvinyl alcohol, it produced very consistent film (' $S$ ' series films). Results were best when percentage of doping was $20 \%$ of organic solvent extract. Detailed results and photographs are provided in Table $\mathbf{2}$ and Fig. (9) respectively. The above material may be a future substitute to fuel cell membrane or may be used in future as sensors or in the form of a wire for conducting electricity.

The average molecular weight of the soluble part of oxy coal in organic solvent was determined by using Gel Permeation Chromatography. The instrumental parameters were flow rate $-1.0 \mathrm{ml} / \mathrm{min}$, Elutent-Tetrahydrofuran and Pressure - 4.8-5.0 M Pa. RI detector was used for the purpose. Considering one main peak in the chromatogram the results are $\mathrm{Mn}-240, \mathrm{Mw}-558, \mathrm{Mw} / \mathrm{Mn}=2.325$.
Considering two peaks (main peak and associated small peak) the results are Mn-232, Mw-835, and Mw/Mn-3.599. When this soluble part of the oxy coal in organic solvent was used as an additive for the preparation of conducting polymer membrane, the quality of the film made was found to be extremely good, uniform and the conductance is in the range $10^{-3}$ to $10^{-4}$ units $\left(\mathrm{Scm}^{-1}\right)$. It is difficult to understand the exact nature and constitution of the product which is yet to be assessed and might be considered as an ongoing subject of research. The material itself has potentiality for its application as an (organic) conductor and may compete with conventional crystalline silicon base used as photo voltaic cells, or as a conducting membrane in fuel cell. Further work is in progress to prepare high molecular weight conducting polymer. The complete set of experiments was repeated five times and consistency in quality and quantity of the product was tested. The results were repeatable and reproducible. The end product was consistent.

\section{CONCLUSION}

For the first time an additive for making conducting polymer membrane has been prepared from coal. The quality of the film made has been extremely good uniform and the conductance is in the range of $10^{-3}$ to $10^{-4}$ units $\left(\mathrm{Scm}^{-1}\right)$. The work are explore for further enhancement in conductivity of coal derivatives. This material may have potential application in fuel cell or may be drown in the form of wire to be conduct electricity, corrosive inhibitors, compact capacitors, antistatic coating, electromagnetic shielding etc. These also have industrial uses like transistors, light emitting diodes, solar cell, lasers used in flat televisions. 


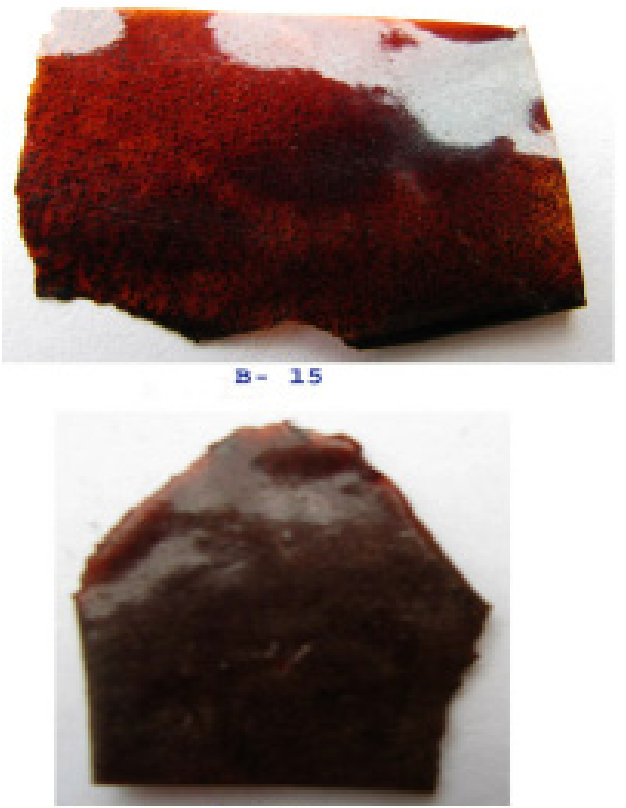

$s_{1}-10 \%$
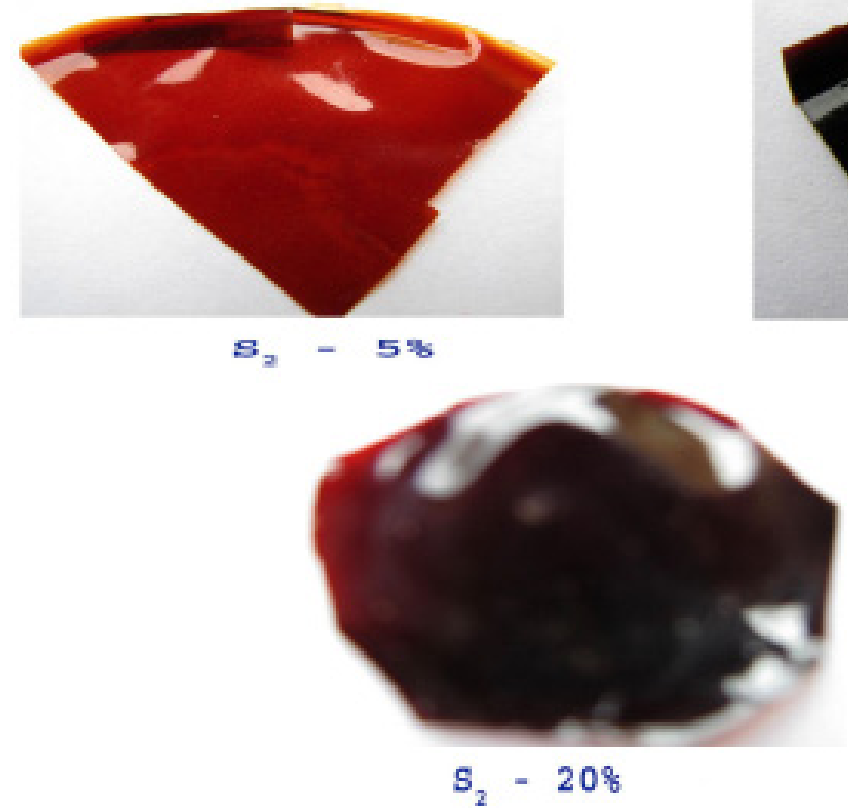

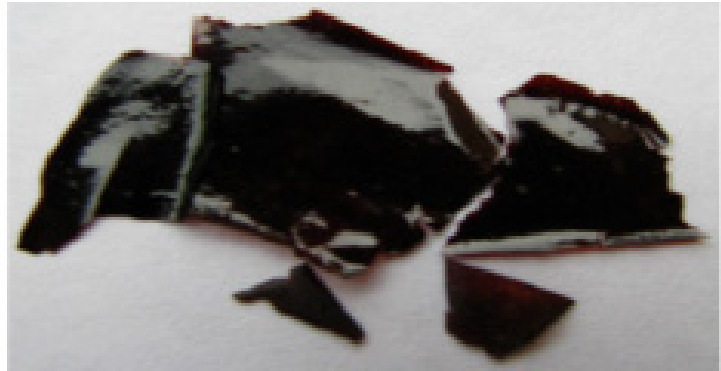

$\mathrm{C}=\mathbf{1 0}$

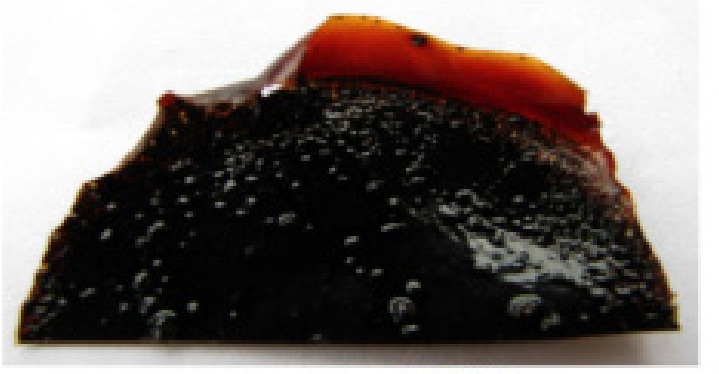

$B_{1}-20 \%$

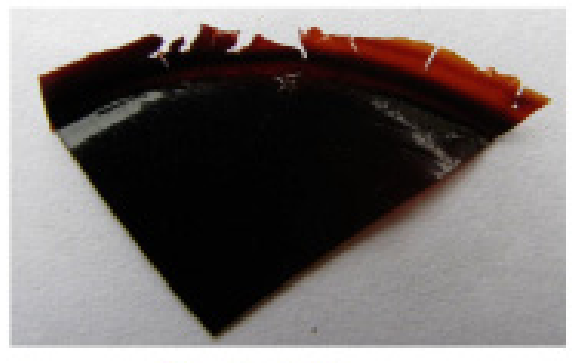

$\mathrm{S}_{2}-10 \mathrm{~s}$

Fig. (9). Photograph of conducting film.

\section{ACKNOWLEDGEMENT}

The authors are thankful to Prof. A.K. Banthia of Materials Science Centre, Indian Institute of Technology, Kharagpur for testing our acetone soluble oxy coal sample by using it for making conducting polymer membrane and for determining average molecular weight (in his laboratory) of our product using GPC.

\section{REFERENCES}

[1] Choudhury, D.; Choudhury, S.S.; Sen, R.; Mukherjee, J.; Ghosh, G.; Srivastava, S.K. Role of nitro group on coal solubilization in aqueous organic solvent. Energy Fuels, 2007, 21, 1006. and references therein.

[2] Ghosh, G.; Banarjee, A.; Mazumdar, B.A. Skeletal structure of coal. Fuel, 1975, 54, 294-295.
[3] Singh, A.R.; Choudhury, D.; Ghosh, G.; Srivastava, S.K Composite polymeric material from coal. 2010, Unpublished work.

[4] Choudhury, D.; Choudhury, S.S.; Sen, R.; Mukherjee, J.; Ghosh, G.; Srivastava, S.K. Direct Sourcing of Coal - part I: solubilization of coal from NE region of India. In: $23^{\text {rd }}$ Annual Pittsburg Coal Conference, Pittsburg, USA, 25-28 ${ }^{\text {th }}$ September, 2006, and references therein.

[5] Given, P.H. The distribution of hydrogen in coal and its relation to coal structure. Fuel, 1960, 39, 147-153.

[6] Hayatsu, R.; Winans, R.E.; Scott, R.G.; Moore, L.P.; Studier, M.H. Oxidation degradation study of coal and solvent refined coal. ACS Symp. Ser., 1978, 71, 108-125.

[7] Bhowmic, J.N.; Mukharjee, P.N.; Lahiri, A. Studies on oxidation of coal at lower temperature. Fuel, 1959, 38, 211.

[8] Heredy, L.A.; Wender, I. Frammbility, ignition and electrostatic properties A.C.S. Div. Fuel Chem. Preprints, 1980, 25-38.

[9] Van Krevelen, D.W. Graphical-statistical method for the study of structure and reaction process of coal. Fuel, 1950, 29, 269-284. 
[10] Lander, W.R.; Snape, C.E. Application of quantitative 13C nuclear magnetic resonan spectroscopy to coal derived materials, Fuel, 1978, 57, 658-662.

[11] Gibson, J. The 1977 Robens coal science lecrure : the constitution of coal and its relevance to coal conversion. J. Inst. Fuel, 1978, 51, 61-81.

[12] Pitt, G.J.; Millward, G.R. In: Coal and modern coal processing: an introduction, Structure analysis of coal. Academic Press, London, UK, 1979, pp. 27-50

[13] Hayatsu, R.; Scott, R.G.; Moore, L.P.; Studier, M.H. Aromatic units in coal. Nature, 1975, 257, 378-380.

[14] Hayatsu, R.; Scott, R.G.; Moore, L.P.; Studier, M.H. Aromatic structure in coal. Nature, 1976, 77, 261.

[15] Hayatsu, R.; Winans, R.E.; Scott, R.G.; Moore, L.P; Studier, M.H. Chacterization of orhanic acids trapped in coal. Nature, 1978, 275, $116-118$
[16] Hayatsu R.; Winans, R.E.; Scott, R.G.; Moore, L.P.; Studier, M.H Trapped organic compounds and aromatic units in coal. Fuel, 1978, $57,541-548$

[17] Joo, J.; Long, J.P. Charge transport of the mesoscopic metallic state in partially cryatalline polyanilines. Phys. Rev., 1998, 57, 95679580 .

[18] Kohlman, R.S.; Epstein, A.J. In: Insulator-metal transition and metallic state of conducting polymers. $2^{\text {nd }}$ ed., Handbook of conducting polymers, $\mathbf{1 9 9 7}, 3,85-121$.

[19] Kohlman, R.S.; Zibold, A.; Tanner, D.B.; Ihas, G.G.; Ishiguro, t.; Min, Y.G.; MacDiarmid, A.G.; Epstein, A.J. Limits for metallic conductivity in conducting polymers, Phys. Rev. Lett., 1997, 78, 3915-3918

(C) Singh et al.; Licensee Bentham Open.

This is an open access article licensed under the terms of the Creative Commons Attribution Non-Commercial License (http://creativecommons.org/licenses/by$\mathrm{nc} / 3.0 /$ ) which permits unrestricted, non-commercial use, distribution and reproduction in any medium, provided the work is properly cited. 